\title{
Learning from agriculture: understanding low-dose antimicrobials as drivers of resistome expansion
}

\author{
Yaqi You and Ellen K. Silbergeld* \\ Department of Environmental Health Sciences, Johns Hopkins Bloomberg School of Public Health, Johns Hopkins University, Baltimore, MD, USA
}

\section{Edited by:}

Joshua D. Nosanchuk, Albert

Einstein College of Medicine, USA

Reviewed by:

Mark Montforts, National Institute

for Public Health and the

Environment, Netherlands

William Hugo Gaze, European

Centre for Environment and Human

Health, UK

\section{*Correspondence:}

Ellen K. Silbergeld, Department of Environmental Health Sciences, Johns Hopkins University

Bloomberg School of Public Health 615 North Wolfe Street, Room

E6644, Baltimore, MD 21205, USA e-mail: esilber2@jhu.edu
Antimicrobial resistance is a growing public health challenge worldwide, with agricultural use of antimicrobials being one major contributor to the emergence and dissemination of antimicrobial resistance (AMR). Globally, most antimicrobials are used in industrial food animal production, a major context for microbiomes encountering low-doses or subtherapeutic-levels of antimicrobial agents from all mechanistic classes. This modern practice exerts broad eco-evolutionary effects on the gut microbiome of food animals, which is subsequently transferred to animal waste. This waste contains complex constituents that are challenging to treat, including AMR determinants and low-dose antimicrobials. Unconfined storage or land deposition of a large volume of animal waste causes its wide contact with the environment and drives the expansion of the environmental resistome through mobilome facilitated horizontal genet transfer. The expanded environmental resistome, which encompasses both natural constituents and anthropogenic inputs, can persist under multiple stressors from agriculture and may re-enter humans, thus posing a public health risk to humans. For these reasons, this review focuses on agricultural antimicrobial use as a laboratory for understanding low-dose antimicrobials as drivers of resistome expansion, briefly summarizes current knowledge on this topic, highlights the importance of research specifically on environmental microbial ecosystems considering AMR as environmental pollution, and calls attention to the needs for longitudinal studies at the systems level.

Keywords: agriculture, antimicrobials, metals, microbiome, resistome, mobilome, environmental pollution

\section{INTRODUCTION}

The intensive production of food animals is a major context for microbiomes encountering low-doses or subtherapeutic-levels of diverse classes of antimicrobial agents. For that reason, this review focuses on food animal production as an important laboratory for understanding the eco- evolutionary (interactions and intersection of ecology and evolutionary biology) mechanisms involved in bacterial responses to low-dose, sub-therapeutic pressures associated with antimicrobials. A majority of agricultural antimicrobials are used as feed additives for growth promotion in livestock and poultry (Silbergeld et al., 2008). This use began in the 1940s in the US, soon after the initiation of large-scale production of these drugs for clinical medicine. From the first approvals to the present, the concentrations of growth promoting antimicrobials (GPAs) in feeds have been stipulated by FDA regulation to deliver sub-therapeutic doses. Redefining GPA use as "therapeutic," "non-therapeutic," or "prophylactic" to comply with regulations in some countries and guidance by the US FDA does not change this condition from the microbial perspective.

This paper will not discuss the hypothesized mechanisms by which GPAs are asserted to increase growth and feed efficiency, since a recent large study by the Perdue Company reported that there were very small or non-significant differences in these outcomes among poultry flocks consuming feeds with or without
GPAs (Engster et al., 2002; Graham et al., 2007). In contrast to earlier studies, including those at Lederle (Stokstad and Jukes, 1958-1959), this is the only study conducted under empirical conditions in poultry production over the lifespan of the animals.

GPA use employs agents from every mechanistic class and currently exceeds all clinical uses in terms of the proportion of total antimicrobial production in the US (Silbergeld et al., 2008; FDA, 2011) and, until recently, in the EU (Teuber, 2001). Information from other regions is not generally available, but given the global expansion of poultry and livestock production using methods similar to those first developed in the US (Graham et al., 2008), it is likely that global use of antimicrobials in animal feeds is also significant (see Arriola, 2011 for study of Peru). As a result, GPAs have had important impacts on selection and dissemination of antimicrobial resistance (AMR) worldwide through the food supply and environmental releases. Moreover, because GPAs are utilized most commonly as mixtures in animal feeds, the gut microbiome of poultry or livestock is exposed to multiple pressures acting on a range of molecular mechanisms associated with resistance development (Davis et al., 2011).

From early in the history of GPA use, it was recognized that the gut microbiome of poultry was responding to selection for resistance to drugs in feeds. Jukes acknowledged this as a truism, 
but discounted any potential risks for human health (1972). With more concern, Starr and Reynolds (1951) reported that Escherichia coli isolated from the gut microflora of poultry flocks fed with streptomycin as a GPA were resistant to streptomycin, as compared to isolates from unexposed flocks. Since that time, numerous studies have documented associations between GPA use and temporal and geographic trends in AMR prevalence in animal wastes, food products, and human populations (documented most completely in studies in Denmark e.g., Aarestrup et al., 2001; Wegener, 2003, also see review by Silbergeld et al., 2008).

The use of molecular, genomic, and metagenomic methods to track AMR genes and AMR strains from food animal production has increased the strength of the evidence on this connection. These methods have also clarified implications of intensive food animal production for human health, demonstrating that the microbiomes of livestock and poultry are reservoirs for AMR pathogens and that resistance determinants can be transferred from these microbiomes to the environment and eventually to humans (Hammerum, 2012). This has been most recently demonstrated for livestock specific strains of methicillin resistant Staphylococcus aureus (van Loo et al., 2007; Waters et al., 2011; Price et al., 2012) and extraintestinal pathogenic E. coli, especially those phylogroups associated with urinary tract infection in humans (Jakobsen et al., 2010). Smet et al. (2011) reported that a plasmid carrying the $b a_{\mathrm{TEM}-52}$ gene encoding ESBL (extended-spectrum $\beta$-lactamase) could be transferred from a poultry strain of $E$. coli into human E. coli under simulated human caecal conditions. The same ESBL genes (including $b l a_{\mathrm{TEM}-52}$ ), ESBL-encoding plasmids and ESBL-producing E. coli strains have been observed in poultry, chicken meat and humans (Leverstein-van Hall et al., 2011).

This paper briefly summarizes current knowledge on this topic and highlights the importance of research specifically on environmental microbial ecosystems for understanding the evolution and persistence of resistance associated with GPA use in agriculture. This reflects the fact that many events related to the emergence of AMR in agricultural settings occur in the context of interactions between the gut microbiome of food animals, such as chickens and pigs, and environmental microbiomes in those ecological niches impacted by disposal of animal wastes. These wastes are normally not treated prior to disposal and often contain AMR bacteria and transmissible genetic elements assembling resistance genes, as well as residual antimicrobials and their degradation products.

\section{CURRENT KNOWLEDGE}

Over the past three decades, research has largely investigated the agricultural setting for AMR emergence primarily for the purpose of understanding the origin of AMR in food borne pathogens. Relatively recently, non-food pathways and the role of the environment have attracted increasing research attention. However, incorporating this knowledge into studies of microbial ecology and evolution as well as into studies of disease outbreaks and attributable risk of infection by drug resistant bacteria is still limited (Ashbolt et al., 2013).

\section{ECO-EVOLUTIONARY CONSEQUENCES OF INDUSTRIAL FOOD ANIMAL PRODUCTION ON THE GUT MICROBIOME OF FOOD ANIMALS}

Current methods and conditions in industrial food animal production are quite different from traditional agronomy in terms of intensity and density as well as the use of GPAs (Silbergeld et al., 2008). These changes are likely to have affected animal gut microbiomes. Looft et al. (2012), using phylogenetic and metagenomic approaches, found that 14 days' exposure to subtherapeutic doses of chlortetracycline, sulfamethazine, and penicillin induced shifts in gut microbiota of pigs. These changes included an increase in the prevalence of Proteobacteria (primarily in E. coli species) and in the abundance and diversity of AMR genes specific to and beyond those used GPAs, as well as selection for other genes related to gene transfer, virulence, energy production, and energy conversion. Population shifts were also observed in the gut microbiome of pigs receiving the GPA tylosin (Kim et al., 2012). Using metagenomic pyrosequencing, Danzeisen et al. (2011) reported that the GPA mixtures of virginiamycin/monensin or tylosin/monensin enriched E. coli populations in the chicken cecal microbiome, along with genes encoding transport systems, type I fimbriae and type IV conjugative secretion systems. That study did not detect significant differences in AMR gene occurrence between GPA treatment and control groups, which may not represent the commercial poultry production conditions. While AMR genes are present in the gut microbiome of free-range chickens (Zhou et al., 2012), a diverse pool of AMR genes is found in conventionally raised chickens (Qu et al., 2008; Zhou et al., 2012).

The mobilome (Siefert, 2009), a collection of all mobile genetic elements (MGEs), is a functional component of the microbiome, and plays an essential role in microbial ecology and evolution by facilitating horizontal gene transfer among microorganisms (Frost et al., 2005; Gillings, 2013). There are some reports on impacts of GPAs on the animal gut mobilome (Danzeisen et al., 2011; Looft et al., 2012), but studies at the systems level are still rare. Antimicrobials, in addition to enriching preexisting AMR genotypes and phenotypes and providing pressure for evolutionary selection for de novo mutations that favor survival (Gullberg et al., 2011), also induce horizontal transfer of MGEs through mechanisms such as bacterial SOS response (Beaber et al., 2003) and translation attenuation (Wozniak and Waldor, 2010). Some recent studies have identified the contributions of GPAs to phagemediated horizontal transfer of AMR genes in the animal gut microbiome. Allen et al. (2011) reported that the GPA mixture Aureomix 500 used in swine feed (containing chlortetracycline, sulfamethazine and penicillin) led to significant population shifts in both phage and bacterial communities, as well as induction of prophages (one type of MGEs) in swine fecal microbiomes. The altered phage metagenomes harbored multiple AMR genes including genes for multidrug resistance. Bearson et al. (2014) reported that the GPA carbadox induced phage mediated transfer of virulence and resistance genes in Salmonella enterica serovar Typhimurium, a human foodborne pathogen that frequently colonizes swine. More investigation is needed for other components of the animal gut mobilome, such as the plasmidome (Kav et al., 2012), before we can fully understand impacts of GPAs on the entire mobilome within the animal gut microbiome. 


\section{ANIMAL WASTES: THE CONNECTOR BETWEEN THE GUT MICROBIOME OF FOOD ANIMALS AND THE ENVIRONMENT}

The gut microbiome of poultry and livestock raised in confinement is transferred into animal excreta, which include the resistome and the mobilome. Also present in animal excreta are unmetabolized GPAs (Kumar et al., 2005; Sarmah et al., 2006) and active metabolites. Thus, the first nexus in the environmental pathway of the dissemination of animal husbandry originated AMR is poultry house litter or cesspits that collect wastes in swine barns (see Figure 1).

Within a confinement house, wastes (solid and liquid) accumulate inputs from animal excreta and other residues like spilled feed containing GPAs into a waste microbiome over the lifetime of a flock or a herd, and often for a longer period when poultry houses are not routinely cleaned between each flock or when septic impoundments are not emptied between herds (Volkova et al., 2009). During this period, the microbiomes of chickens and house litter interact and exchange organisms and resistance

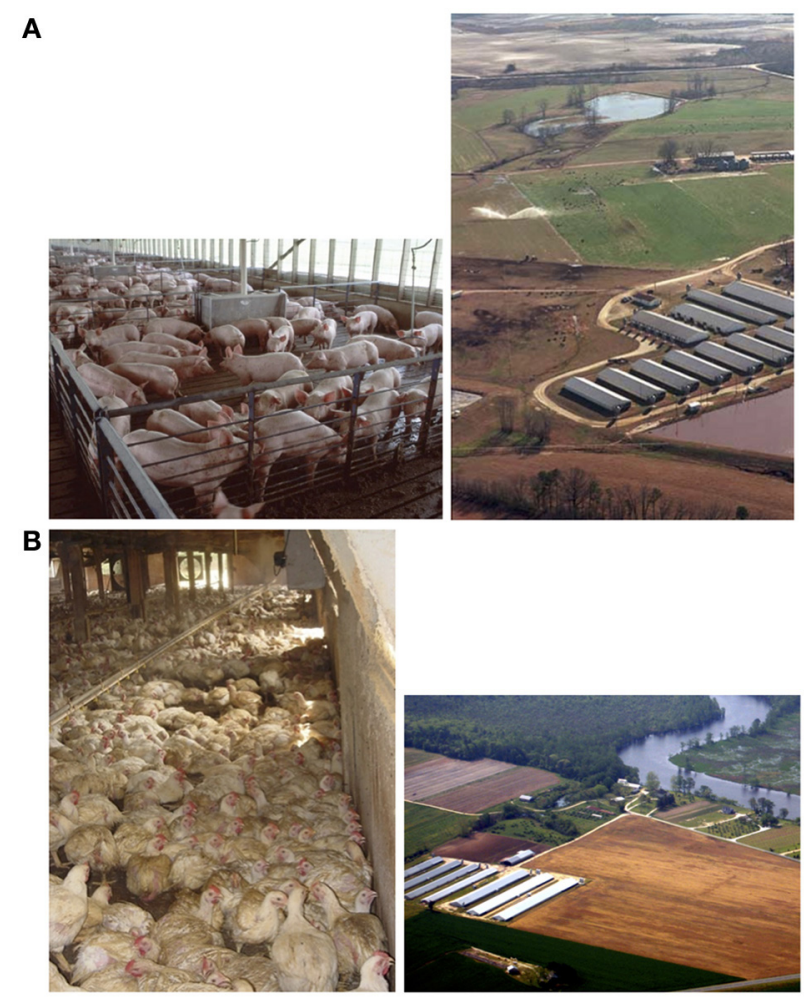

FIGURE 1 | (A) (left) Pigs in confinement house (photo USDA). Note slatted floor; wastes (including excreta and spilled feed) accumulate on this surface and are periodically washed down into a cesspit below the building. (right) A view of a swine production operation showing open cesspits that collect drainage from animal houses; disposal of these wastes involves spraying of liquids (photo S Wing). (B) (left) Chickens in a Maryland poultry house. Flocks are housed directly on litter, which contains excreta (as evident from the birds) as well as spilled feed. Litter is removed infrequently from poultry houses (photo J Graham). (right) The lower Pocomoke River, with poultry houses and land disposal of poultry waste (source: Integration and Application Network, University of Maryland Center for Environmental Sciences). genes (Cressman et al., 2010; Shanmugasundaram et al., 2011). Eco-evolutionary events in the litter microbiome have not been carefully studied. But poultry litter is known to be a reservoir of AMR bacteria and resistance determinants, resistance-encoding MGEs and residual antimicrobials (Nandi et al., 2004; Furtula et al., 2009; Graham et al., 2009a; Cheng et al., 2013).

Environmental dissemination of the food-animal-associated microbiome and resistome occurs through waste holding and disposal. Food animal wastes are first released to the environment through on site storage (usually in open sheds for poultry or open impoundments for swine) and then discharged into the environment more broadly by land application as shown in Figure 1 . The sites of land disposal may be close to or very distant from the sites of poultry or swine production (Leibler et al., 2009). Once released into the external environment either by unconfined storage or by deposition on land, the microbial and chemical constituents of animal wastes can be widely dispersed mainly through dust, air, and water movement, as well as by animal movement (flies, rodents, and wild birds) (Graham et al., 2009b).

Because of the intensity of food animal production in the US and other countries, this constitutes a major source of all gut microbiota being transferred to the environment (Silbergeld et al., 2008). Unlike human biosolids, no treatment is required prior to discharge of animal wastes, which are almost entirely (>90\%) disposed of onto land (Graham and Nachman, 2010). Storage of poultry house litter or of swine waste, without specific composting procedures, does not reduce the burden of pathogens and AMR determinants (Gerba and Smith, 2005; Graham et al., 2009a). More intensive composting, though more effective in attenuating microbial loadings in wastes, does not significantly reduce loadings of AMR genes (Storteboom et al., 2007). Even multiple treatment lagoons are unable to completely remove AMR genes (McKinney et al., 2010).

For these characteristics of animal wastes-complex constituents, large volume, insufficient waste management, and broad contact with the environment- the appropriate focus for understanding the emergence and dissemination of AMR driven by use of subtherapeutic GPAs in agriculture is in the interactions between animal wastes and the environment. Intensive animal production operations and associated environmental compartments have been characterized as "genetic reactors" where new genotypes and phenotypes of resistance can evolve through genetic exchange and recombination, and re-enter humans and animals (Baquero et al., 2008). We conceive of a series of dynamic interactions between environmental microbiomes and the altered gut microbiome of poultry flocks that is represented within poultry house waste, which in turn integrates microbial loadings from multiple flocks within each house. This is shown in Figure 2 (Davis et al., 2011).

\section{THE ENVIRONMENTAL MICROBIOME AND LOW-LEVEL ANTIMICROBIAL PRESSURE FROM AGRICULTURE}

The environment is both the main receptor for animal wastes containing AMR determinants, particularly those on MGEs (Heuer et al., 2011), and the locus of the natural resistome (D'Costa et al., 2006, 2007) and mobilome (Siefert, 2009; Gillings, 2013) which together constitute the genetic resources available to microbial 


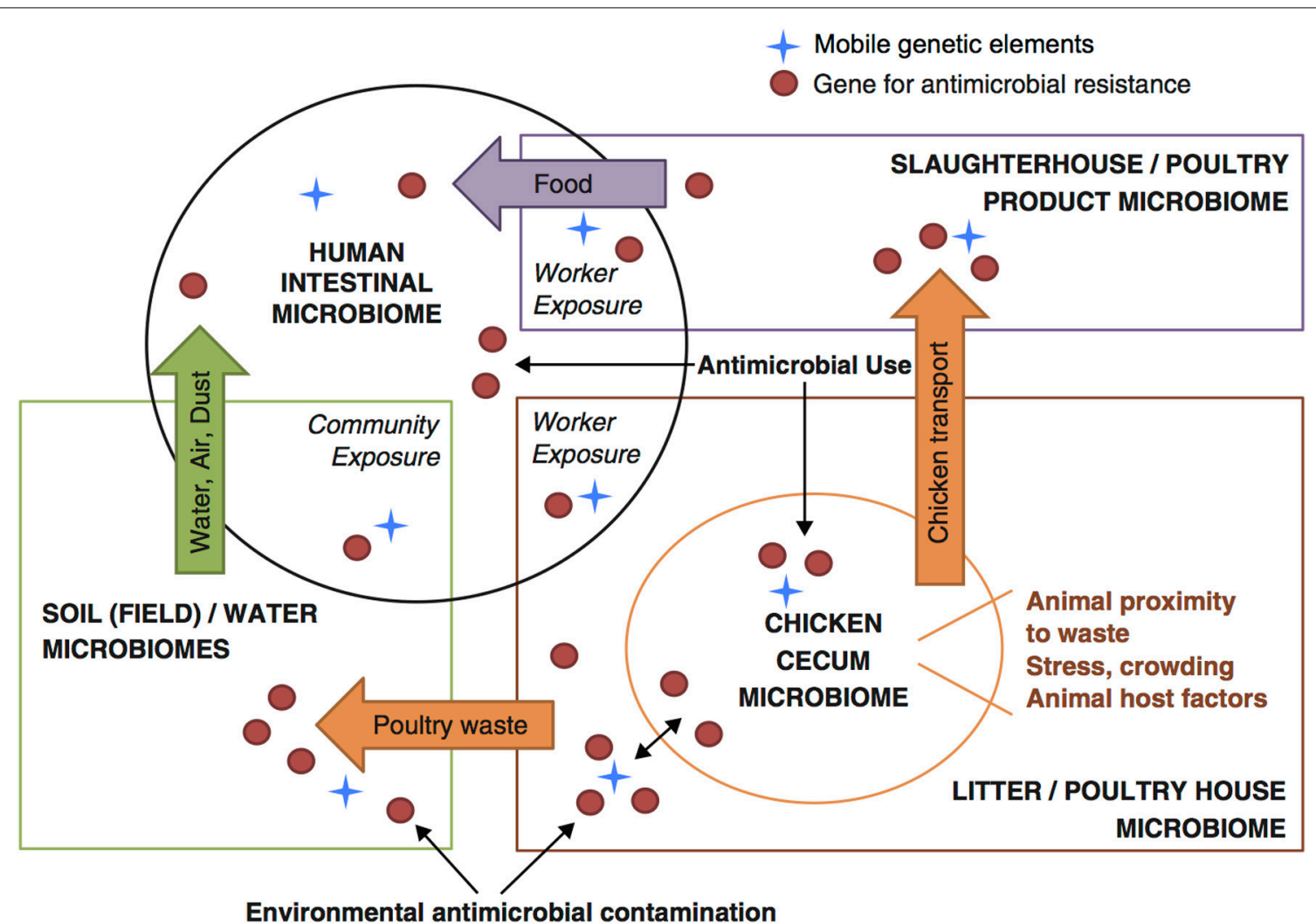

FIGURE 2 | Conceptual framework for understanding flow of resistance genes and mobile genetic elements across microbiomes within food animals, the environment, and human populations (based on Davis et al., 2011).

communities for surviving antimicrobial stress and the genetic machinery to transfer these genetic resources among bacteria within and among different microbial communities. The environmental resistome, which encompasses both natural constituents as well as inputs from anthropogenic activities like agriculture, is relevant to human health as it can be a source of resistance determinants found in human pathogens, particularly through the mobilome (Forsberg et al., 2012; Perry and Wright, 2013).

There is ample evidence in the literature on the impacts of intensive food animal production on the occurrence of AMR in directly or indirectly affected environmental compartments (including soils, sediments, and water) (reviewed by Joseph et al., 2001; D'Costa et al., 2007; Ghosh and LaPara, 2007; Stine et al., 2007; Silbergeld et al., 2008; Graham et al., 2009a; Martinez, 2009; Knapp et al., 2010; Heuer et al., 2011; You et al., 2012, 2013; Gaze et al., 2013; Jones et al., 2013; Wei et al., 2013). Using quantitative methods such as real-time PCR and LC-MS/MS, correlations have been demonstrated between the occurrence/abundance of AMR genes and the extent of antimicrobial use or drug concentrations in animal husbandry environments (Smith et al., 2004; Peak et al., 2007; McKinney et al., 2010; Wu et al., 2010; Zhu et al., 2013). These relationships may involve multiple mechanisms including the simultaneous loading of both genes and drugs into the ecosystem and/or in situ selection for AMR in the environment due to inputs of antimicrobials, metals, and other residues. Until recently it was thought that the concentrations of antimicrobial compounds or their degradation products in the environment, which usually range from $\mu \mathrm{g} / \mathrm{kg}$ to $\mathrm{mg} / \mathrm{kg}$ in sediment or soil samples (Kemper, 2008), were not high enough to select for resistance. However, laboratory studies have demonstrated that low concentrations of antimicrobials in the same range are sufficient to select for resistance through several mechanisms (Kohanski et al., 2010; Gullberg et al., 2011). A study involving both field and laboratory research and coupled with modeling reported a selective and persistent effect of sulfadiazine in pig manure on resistance genes in soil microbiota (Heuer et al., 2008). Interactions between drugs (and their degradation products) and the soil microbiome are influenced by the physicochemical properties of each drug, which affect their potential bioavailability in the environment such as soils (Tolls, 2001; Hamscher et al., 2005; Kemper, 2008). Also antimicrobials undergo biotic/abiotic degradation in the environment (Sarmah et al., 2006), and only some of the degradation products exhibit antimicrobial potency (Halling-Sørensen et al., 2002). Data on the bioavailability of agricultural antimicrobials in situ are still missing (Heuer et al., 2011).

There are demonstrated links between agricultural antimicrobial use and expansion of the environmental resistome and mobilome (reviewed by Nandi et al., 2004; Ghosh and LaPara, 2007; Heuer et al., 2008, 2011; Zhang et al., 2009; Allen et al., 2010; Gaze et al., 2013; Zhu et al., 2013). A historical analysis 
of soil samples collected from 1940 to 2008 in the Netherlands found an exponential increase of AMR genes in agricultural soils (Knapp et al., 2010). Horizontal gene transfer largely contributes to the proliferation and persistence of AMR genes in the environment. After being introduced into the environment microbiome, animal-waste borne bacteria can transfer their AMR genes to indigenous bacteria through conjugation due to the frequent assembly of AMR genes on integrons, transposons and plasmids in the animal waste microbiome (Andrews et al., 2004; Nandi et al., 2004; Binh et al., 2008; Byrne-Bailey et al., 2011; Heuer et al., 2011; Zhu et al., 2013). This process can be stimulated by enhanced nutrient availability from animal wastes (van Elsas et al., 2003). Even after AMR bacteria of the animal gut microbiome died, their AMR genes can persist and be taken up by soil bacteria through transformation (Lorenz and Wackernagel, 1994) and thus proliferate in the environmental microbiome. Positive correlations have been observed between the concentration of antimicrobials and the abundance of MGEs carrying AMR genes in soil or water (Knapp et al., 2008; Zhu et al., 2013). But it is unclear whether this is due to enhanced horizontal gene transfer or selection on the recipient populations after transfer. Longitudinal and systemic studies on the environmental resistome and mobilome in response to agricultural stress are needed to assess its broad impacts on microbial ecosystems.

We have studied the presence of drugs, resistant bacteria, resistance genes, and resistance-encoding plasmids in soil microbiota near a waste storage site at a concentrated poultry production operation in the US in comparison to several sites within a protected state forest in the same region (You et al., 2012). Neither tetracycline nor chlortetracycline was detected in the forest soil samples, but measurable levels $(<10 \mu \mathrm{g} / \mathrm{kg})$ were detected in the farm samples from near the storage site. Farm samples also contained a high proportion of tetracycline resistant bacteria as compared to forest samples. Resistance genes (tet $M, O$ and ermA, $B, C)$ as well as plasmids containing tet $L$ were only detected in farm soils. While tet $L$ was found in both farm and forest samples, its prevalence was much higher in the former. In all of the perspectives, soil from a less waste-affected site at the same concentrated poultry production operation showed no significant difference from forest soil. These results are similar to those published on soils impacted by swine wastes (Agerso et al., 2006; Ghosh and LaPara, 2007). The results of our study suggested that resistance could persist within the soil microbiome. A study by Sengelov et al. (2003) reported persistence of resistant isolates for 300 days after application of swine wastes to soil. Another study by Ghosh and LaPara (2007) reported that bacterial resistance levels in soil with excessive application of swine manure were sustained for at least 18 months.

In summary, poultry and livestock wastes are an important anthropogenic source of antimicrobial pressure, at low levels, for the microbiomes of hosts and environments. The ecological and evolutionary events in the environmental microbiome in response to animal waste inputs include interactions between antimicrobials (also other chemicals as exemplified in the next paragraph) and the environmental microbiome; interactions between the waste microbiome and the environmental microbiome; and interactions between the environmental microbiome and resistance genes in waste. These interactions are relevant to the expansion and persistence of the resistome within the environmental microbiome, which may in turn expose human microbiomes through multiple pathways. Because of the complex nature of these interactions and the diversity of environmental microbiomes, studies at a systems level using advanced "omics" methods are in particular need.

\section{INTERACTING STRESSORS IN THE GUT AND ENVIRONMENTAL MICROBIOMES-ANTIMICROBIALS AND METALS}

Feeds for food animals are complex mixtures of natural products from both crop and animal sources, as well as recycled wastes and other additives (Sapkota et al., 2007). As a result, there are multiple potential stressors, in addition to GPAs, presented via feeds to food animal gut microbiomes. These include metals that are known to co-select for resistance in bacteria (Baker-Austin et al., 2006). For example, arsenicals are used as coccidiostats and growth promoters, copper and zinc are used as trace element supplements, mercury is present as a contaminant in fish meal (a major constituent of poultry feeds), as well as a range of metals in industrial waste byproducts permitted as additives to animal feeds (in the US). These metals are not metabolized (except in the case of arsenic, where chicken gut microbiota metabolize roxarsone, an organoarsenical, into the more toxic form of inorganic arsenic Stolz et al., 2007) and thus like antimicrobial drugs, they are excreted into wastes (Garbarino et al., 2003; Jackson et al., 2003) and transferred into soil through waste disposal (Gupta and Charles, 1999; Rutherford et al., 2003).

Previous microbiological research under both laboratory and field conditions have reported on interactions between these metals and antimicrobials in terms of co-selection for and co-transfer of resistance among bacteria via MGEs containing both metal and drug resistance genes (Bass et al., 1999; Baker-Austin et al., 2006; Singer et al., 2006; Stepanauskas et al., 2006; Wright, 2007; Tuckfield and McArthur, 2008; Novo et al., 2013). Significant positive correlations were observed between tet genes and several metals in a study of swine waste lagoons (McKinney et al., 2010), and between total AMR genes and copper in a study of manure, compost, and soils from swine farm (Zhu et al., 2013).

These interactions have extended to human health concerns. There is evidence that exposure of human hosts to mercury increases odds of their carrying antibiotic resistant E. coli (Skurnik et al., 2010). It has been known for some time that $\operatorname{tcr} B$, a copper resistance gene, is transferrable and linked to genes encoding macrolide and glycopeptide resistance (Hasman and Aarestrup, 2002). This was recently confirmed independently by two research groups (Amachawadi et al., 2013; Silveira et al., 2014) who also showed that $t c r B$ could be transferred by conjugation among enterococci from pigs, poultry, and cattle along with resistance genes for erythromycin, tetracycline, vancomycin, ampicillin, and gentamycin. Cavaco et al. (2011) reported that cadmium and zinc drive co-selection for methicillin resistance in Staphylococcus aureus through horizontal transfer of plasmids containing genes for both methicillin and metal resistance (mec and $c z r$ ).

These findings indicate the need to consider interaction effects of antimicrobials and other stressors within agricultural settings in terms of driving AMR emergence and dissemination, 
particularly in light of the complex nature of manufactured feeds utilized in food animal production.

\section{CONCLUSIONS: ANTIMICROBIAL RESISTANCE IS A FORM OF ENVIRONMENTAL POLLUTION}

Resistance dissemination involves multiple microbiomes, each having a complex ensemble of microbes, particularly in the case of the environmental microbiome. These microbiomes are encountering diverse interacting stressors, and gene flow occurs through these microbiomes. Systems-biology approaches driven by "omics" methods (Raes and Bork, 2008) can improve our understanding of mechanisms of AMR development and persistence. Meanwhile, the "eco-health" perspective that takes into account linkages between ecosystems and health (Zinsstag et al., 2011) can improve our health practices, in particular those prior to human exposure.

An intriguing concept has been proposed, to consider AMR as environmental pollution, most comprehensively explained by Martinez (2009). There are some studies utilizing this concept to track AMR genes in landscapes, most frequently in studies of watersheds (Pei et al., 2006; Pruden et al., 2006). But this research, important as it is, still does not fully exploit the importance of the concept. If we think about "resistance" as a material thing, not just a behavior of bacteria, we can consider how this material behaves in environmental compartments such as water, soils, and sediments. Because of the importance of the environment as a locus for the emergence, persistence, and dissemination of AMR, particularly in relevance to low level AMR pressure derived from agriculture, this proposal merits further analysis at the theoretical level as well as more extensive field research in impacted environments.

In thinking about resistance as a pollutant, we can consider the approaches of environmental research in studying chemical pollutants. In many respects, resistance genes have the same properties that we consider in evaluating pollutants like pesticides.

Three characteristics are important in environmental health: hazard, persistence, and bioaccumulation. That is, does a substance in itself have properties that could seriously harm human health, does the substance remain unchanged in the environment without being broken down by natural processes, and finally is the substance taken up by organisms such that its levels increase over time in those species.

We can certainly say that an AMR gene is hazardous to human health because when it is present in a pathogenic bacterial cell or population it can result in failure of medical treatment of infection. Thus, resistance genes require incorporation into an organism to express their hazard, which is not so different from thinking the conversion of mercury into methyl mercury and its incorporation into fish. Low dose issues are important in understanding the hazards of agricultural use of antimicrobials since, similar to the hazards of some environmental chemicals, the pressure for selection for resistance may be more significant at lower doses (Vandenberg, 2014). This has been shown for failures of clinical antimicrobial treatment (Schentag et al., 2007).

The second characteristic of importance is persistence of resistance genes in the environment, about which we know relatively little. Resistance genes can survive in soils for long periods of time (Heuer et al., 2011). One recent study demonstrated that purified DNA from transplastomic plants encoding resistance to streptomycin could be detected as long as 4 years after being added into soils, and that these resistance genes could still be taken up by bacteria and incorporated into their chromosomal DNA for expression (Pontiroli et al., 2010). Persistence of resistant phenotypes is complex. There are both theoretical and empirical data to challenge the standard model of evolutionary selection for AMR or for susceptibility depending upon the presence or absence of antimicrobial stress (Andersson and Hughes, 2010). Theoretically, Levin and others have demonstrated that there are two evolutionary "choices" for resistant bacteria to adapt to the absence of stress when the expression of resistance exacts some cost to the bacterial populations in terms of physiological demands or reproductive rate (Levin et al., 2000; Rozen et al., 2007). One "choice" is reversion to susceptibility; the other choice is selection for a means to reduce this cost. Both choices involve mutation either back to the wild type gene or to a change in some other gene that is associated with increased Malthusian fitness. The second path may be a more adaptive strategy for microbial communities under continuous or periodic stress from antimicrobials, as in an environment with inputs of antimicrobial drugs from agriculture.

The third key characteristic of chemical pollutants in the environment in terms of raising alerts is bioaccumulation and biomagnification, or uptake and retention of chemicals in biota and increase in concentration within ecosystems through food chains. DNA (extracellular or intracellular) in the environment, like chemicals in the environment, can be accumulated by bacteria through transformation (Lorenz and Wackernagel, 1994) and on hierarchical compositions of MGEs through insertion (Frost et al., 2005). Biomagnification of a resistance gene occurs within microbiomes by the expansion of bacterial populations or MGEs carrying that gene. That is, (1) once a novel gene is taken up and incorporated into a bacterial genome, when that organism divides, its daughter cells each contain the new gene, which is a highly efficient process of increasing the total amount of that gene; or (2) once a novel gene is inserted in a MGE, when the MGE invades a bacterial community, diverse populations acquire the new gene through repeated infections.

\section{RESEARCH NEEDS}

From this brief review, we can identify some important research needs relevant to increasing our understanding of low dose antimicrobial exposures (including but not limited to GPAs in agriculture) in the context of microbial ecology and evolution. These questions in many cases can best answered with longitudinal studies using state of the art methods to interrogate the microbiome and its constituent elements such as the resistome and the mobilome. As noted by others, there is a critical lack of such studies at the systems level that permit examining associations between changes in the environmental resistome and well annotated changes in the drivers related to agricultural land use (Singer et al., 2006; Shade et al., 2013). 
(1) What does it mean to expose the microbiome to multiple antimicrobial and metal stressors at low doses?

(2) What does it mean to stress the gut microbiome continuously over the lifetime and generations of food animals in terms of resistance and other changes at the microbiome level?

(3) What events occur in food animal wastes in terms of expanding the resistome? What is the contribution of the continued presence of residual antimicrobials in wastes?

(4) What events occur in soils where food animal wastes are repeatedly applied and in sediments impacted by agricultural runoff? What is the contribution of the continued presence of antimicrobials at low concentrations in soils and sediments?

(5) How long is the persistence of resistant bacteria in animal wastes? How long is the persistence of resistance genes in the soil or sediment ecosystem?

(6) How can we quantify the contribution of food animal production using GPAs to the expansion of the environmental and human host resistome/mobilome?

(7) What are the major pathways from environmental compartments such as soils or sediments to humans; to what extent do these pathways involve passage through the microbiomes of wild or other domesticated animals?

(8) What are the most effective and efficient methods for studying these events at the system level?

\section{REFERENCES}

Aarestrup, F. M., Seyfarth, A. M., Emborg, H. D., Pedersen, K., Hendriksen, R. S., and Bager, F. (2001). Effect of abolishment of the use of antimicrobial agents for growth promotion on occurrence of antimicrobial resistance in fecal enterococci from food animals in Denmark. Antimicrob. Agents Chemother. 45, 2054-2059. doi: 10.1128/AAC.45.7.2054-2059.2001

Agerso, Y., Wulff, G., Vaclavik, E., Halling-Sorensen, B., and Jensen, L. B. (2006). Effect of tetracycline residues in pig manure slurry on tetracycline-resistant bacteria and resistance gene tet $(\mathrm{M})$ in soil microcosms. Environ. Int. 32, 876-882. doi: 10.1016/j.envint.2006.05.008

Allen, H. K., Donato, J., Wang, H. H., Cloud-Hansen, K. A., Davies, J., and Handelsman, J. (2010). Call of the wild: antibiotic resistance genes in natural environments. Nat. Rev. Microbiol. 8, 251-259. doi: 10.1038/nrmicro2312

Allen, H. K., Looft, T., Bayles, D. O., Humphrey, S., Levine, U. Y., Alt, D., et al. (2011). Antibiotics in feed induce prophages in swine fecal microbiomes. MBio 2, e00260-e00211. doi: 10.1128/mBio.00260-11

Amachawadi, R. G., Scott, H. M., Alvarado, C. A., Mainini, T. R., Vinasco, J., Drouillard, J. S., et al. (2013). Occurrence of the transferable copper resistance gene $t c r B$ among fecal enterococci of US feedlot cattle fed copper-supplemented diets. Appl. Environ. Microb. 79, 4369-4375. doi: 10.1128/AEM.00503-13

Andersson, D. I., and Hughes, D. (2010). Antibiotic resistance and its cost: is it possible to reverse resistance? Nat. Rev. Microbiol. 8, 260-271. doi: 10.1038/nrmicro2319

Andrews, R. E. Jr., Johnson, W. S., Guard, A. R., and Marvin, J. D. (2004). Survival of enterococci and Tn916-like conjugative transposons in soil. Can. J. Microbiol. 50, 957-966. doi: 10.1139/w04-090

Arriola, C. S. (2011). Antimicrobial Resistant Bacteria and Use of Antimicrobials in Pig Farming in Peru. Ph.D. thesis, Johns Hopkins University.

Ashbolt, N. J., Amézquita, A., Backhaus, T., Borriello, P., Brandt, K. K., Collignon, P., et al. (2013). Human health risk assessment (HHRA) for environmental development and transfer of antibiotic resistance. Environ. Health Perspec. 121, 993-1001. doi: 10.1289/ehp.1206316

Baker-Austin, C., Wright, M. S., Stepanauskas, R., and McArthur, J. V. (2006). Coselection of antibiotic and metal resistance. Trends Microbiol. 14, 176-182. doi: 10.1016/j.tim.2006.02.006

Baquero, F., Martinez, J. L., and Cantón, R. (2008). Antibiotics and antibiotic resistance in water environments. Curr. Opin. Biotech. 19, 260-265. doi: 10.1016/j.copbio.2008.05.006
Bass, L., Liebert, C. A., Lee, M. D., Summers, A. O., White, D. G., Thayer, S. G., et al. (1999). Incidence and characterization of integrons, genetic elements mediating multiple-drug resistance, in avian Escherichia coli. Antimicrob. Agents Chemother. 43, 2925-2929.

Beaber, J. W., Hochhut, B., and Waldor, M. K. (2003). SOS response promotes horizontal dissemination of antibiotic resistance genes. Nature 427, 72-74. doi: 10.1038/nature02241

Bearson, B. L., Allen, H. K., Brunelle, B. W., Lee, I., Casjens, S. R., and Stanton, T. B. (2014). The agricultural antibiotic carbadox induces phage-mediated gene transfer in Salmonella. Front. Microbiol. 5:52. doi: 10.3389/fmicb.2014. 00052

Binh, C. T. T., Heuer, H., Kaupenjohann, M., and Smalla, K. (2008). Piggery manure used for soil fertilization is a reservoir for transferable antibiotic resistance plasmids. FEMS Microbiol. Ecol. 66, 25-37. doi: 10.1111/j.15746941.2008.00526.x

Byrne-Bailey, K. G., Gaze, W. H., Zhang, L., Kay, P., Boxall, A., Hawkey, P. M., et al. (2011). Integron prevalence and diversity in manured soil. Appl. Environ. Microb. 77, 684-687. doi: 10.1128/AEM.01425-10

Cavaco, L. M., Hasman, H., and Aarestrup, F. M. (2011). Zinc resistance of Staphylococcus aureus of animal origin is strongly associated with methicillin resistance. Vet. Microbiol. 150, 344-348. doi: 10.1016/j.vetmic.2011. 02.014

Cheng, W., Chen, H., Su, C., and Yan, S. (2013). Abundance and persistence of antibiotic resistance genes in livestock farms: a comprehensive investigation in eastern China. Environ. Int. 61, 1-7. doi: 10.1016/j.envint. 2013.08.023

Cressman, M. D., Yu, Z., Nelson, M. C., Moeller, S. J., Lilburn, M. S., and Zerby, H. N. (2010). Interrelations between the microbiotas in the litter and in the intestines of commercial broiler chickens. Appl. Environ. Microbiol. 76, 6572-6582. doi: 10.1128/AEM.00180-10

Danzeisen, J. L., Kim, H. B., Isaacson, R. E., Tu, Z. J., and Johnson, T. J. (2011). Modulations of the chicken cecal microbiome and metagenome in response to anticoccidial and growth promoter treatment. PLoS ONE 6:e27949. doi: 10.1371/journal.pone.0027949

Davis, M. F., Silbergeld, E., Price, L. B., and Liu, C. M.-H. (2011). An ecological perspective on U.S. industrial poultry production: the role of anthropogenic ecosystems on the emergence of drug-resistant bacteria from agricultural environments. Curr. Opin. Microbiol. 14, 244-250. doi: 10.1016/j.mib.2011. 04.003

D'Costa, V. M., Griffiths, E., and Wright, G. D. (2007). Expanding the soil antibiotic resistome: exploring environmental diversity. Curr. Opin. Microbiol. 10, 481-489. doi: 10.1016/j.mib.2007.08.009

D’Costa, V. M., McGrann, K. M., Hughes, D. W., and Wright, G. D. (2006). Sampling the antibiotic resistome. Science 311, 374-377. doi: 10.1126/science. 1120800

Engster, H. M., Marvil, D., and Stewart-Brown, B. (2002). The effect of withdrawing growth promoting antibiotics from broiler chickens: a long-term commercial industry study. J. Appl. Poult. Res. 11, 431-436. doi: 10.1093/japr/ 11.4.431

FDA. (U.S. Food and Drug Administration). (2011). 2011 Summary Report on Antimicrobials Sold or Distributed for Use in Food-Producing Animals.

Forsberg, K. J., Reyes, A., Wang, B., Selleck, E. M., Sommer, M. O., and Dantas, G. (2012). The shared antibiotic resistome of soil bacteria and human pathogens. Science 337, 1107-1111. doi: 10.1126/science.1220761

Frost, L. S., Leplae, R., Summers, A. O., and Toussaint, A. (2005). Mobile genetic elements: the agents of open source evolution. Nat. Rev. Microbiol. 3, 722-732. doi: 10.1038/nrmicro1235

Furtula, V., Farrell, E. G., Diarrassouba, F., Rempel, H., Pritchard, J., and Diarra, M. S. (2009). Veterinary pharmaceuticals and antibiotic resistance of Escherichia coli isolates in poultry litter from commercial farms and controlled feeding trials. Poult. Sci. 89, 180-188. doi: 10.3382/ps.2009-00198

Garbarino, J. R., Bednar, A. J., Rutherford, D. W., Beyer, R. S., and Wershaw, R. L. (2003). Environmental fate of roxarsone in poultry litter. I. Degradation of roxarsone during composting. Environ. Sci. Technol. 37, 1509-1514. doi: $10.1021 / \mathrm{es} 026219 \mathrm{q}$

Gaze, W. H., Krone, S. M., Larsson, D. G. J., Li, X.-Z., Robinson, J. A., Simonet, P., et al. (2013). Influence of humans on evolution and mobilization of environmental antibiotic resistome. Emerg. Infect. Dis. 19, e120871. doi: 10.3201/eid1907.120871 
Gerba, C. P., and Smith, J. E. (2005). Sources of pathogenic microorganisms and their fate during land application of wastes. J. Environ. Qual. 34, 42-48. doi: 10.2134/jeq2005.0042

Ghosh, S., and LaPara, T. M. (2007). The effects of subtherapeutic antibiotic use in farm animals on the proliferation and persistence of antibiotic resistance among soil bacteria. ISME J. 1, 191-203. doi: 10.1038/ismej.2007.31

Gillings, M. R. (2013). Evolutionary consequences of antibiotic use for the resistome, mobilome and microbial pangenome. Front. Microbiol. 4:4. doi: 10.3389/fmicb.2013.00004

Graham, J. P., Boland, J. J., and Silbergeld, E. (2007). Growth promoting antibiotics in food animal production: an economic analysis. Public Health Rep. 122, 79-87.

Graham, J. P., Evans, S. L., Price, L. B., and Silbergeld, E. (2009a) Fate of antimicrobial-resistant enterococci and staphylococci and resistance determinants in stored poultry litter. Environ. Res. 109, 682-689. doi: 10.1016/j.envres.2009.05.005

Graham, J. P., Silbergeld, E., Price, L. B., Evans, S. L., and Graczyk, T. K. (2009b). Antibiotic resistant enterococci and staphylococci isolated from flies collected near confined poultry feeding operations. Sci. Total Environ. 407, 2701-2710. doi: 10.1016/j.scitotenv.2008.11.056

Graham, J. P., Leibler, J. H., Price, L. B., Otte, J. M., Pfeiffer, D. U., Tiensin, T., et al. (2008). The animal-human interface and infectious disease in industrial food animal production: rethinking biosecurity and biocontainment. Public Health Rep. 123, 282-299.

Graham, J. P., and Nachman, K. E. (2010). Managing waste from confined animal feeding operations in the United States: the need for sanitary reform. J. Water Health 8, 646-670. doi: 10.2166/wh.2010.075

Gullberg, E., Cao, S., Berg, O. G., Ilbäck, C., Sandegren, L., Hughes, D., et al. (2011). Selection of resistant bacteria at very low antibiotic concentrations. PLoS Pathog. 7:e1002158. doi: 10.1371/journal.ppat.1002158

Gupta, G., and Charles, S. (1999). Trace elements in soils fertilized with poultry litter. Poult. Sci. 78, 1695-1698. doi: 10.1093/ps/78.12.1695

Halling-Sørensen, B., Sengeløv, G., and Tjørnelund, J. (2002). Toxicity of tetracyclines and tetracycline degradation products to environmentally relevant bacteria, including selected tetracycline-resistant bacteria. Arch. Environ. Con. Tox. 42, 263-271. doi: 10.1007/s00244-001-0017-2

Hammerum, A. M. (2012). Enterococci of animal origin and their significance for public health. Clin. Microbiol. Infect. 18, 619-625. doi: 10.1111/j.14690691.2012.03829.x

Hamscher, G., Pawelzick, H. T., and Höper, H. (2005). Different behavior of tetracyclines and sulfonamides in sandy soils after repeated fertilization with liquid manure. Environ. Toxicol. Chem. 24, 861-868. doi: 10.1897/ 04-182R.1

Hasman, H., and Aarestrup, F. M. (2002). tcrB, a gene conferring transferable copper resistance in Enterococcus faecium: occurrence, transferability, and linkage to macrolide and glycopeptide resistance. Antimicrob. Agents Chemother. 46, 1410-1416. doi: 10.1128/AAC.46.5.1410-1416.2002

Heuer, H., Focks, A., Lamshöft, M., Smalla, K., Matthies, M., and Spiteller, M. (2008). Fate of sulfadiazine administered to pigs and its quantitative effect on the dynamics of bacterial resistance genes in manure and manured soil. Soil Biol. Biochem. 40, 1892-1900. doi: 10.1016/j.soilbio. 2008.03.014

Heuer, H., Schmitt, H., and Smalla, K. (2011). Antibiotic resistance gene spread due to manure application on agricultural fields. Curr. Opin. Microbiol. 14, 236-243. doi: 10.1016/j.mib.2011.04.009

Jackson, B. P., Bertsch, P. M., Cabrera, M. L., Camberato, J. J., Camberato, J. J. Seaman, J. C., et al. (2003). Trace element speciation in poultry litter. J. Environ. Qual. 32, 535-540. doi: 10.2134/jeq2003.5350

Jakobsen, L., Spangholm, D. J., Pedersen, K., Jensen, L. B., Emborg, H.D., Agersø, Y., et al. (2010). Broiler chickens, broiler chicken meat, pigs and pork as sources of ExPEC related virulence genes and resistance in Escherichia coli isolates from community-dwelling humans and UTI patients. Int. J. Food Microbiol. 142, 264-272. doi: 10.1016/j.ijfoodmicro. 2010.06.025

Jones, B. A., Grace, D., Kock, R., Alonso, S., Rushton, J., Said, M. Y. et al. (2013). Zoonosis emergence linked to agricultural intensification and environmental change. Proc. Natl. Acad. Sci. U.S.A. 110, 8399-8404. doi: $10.1073 /$ pnas. 1208059110
Joseph, S. W., Hayes, J. R., English, L. L., Carr, L. E., and Wagner, D. D. (2001). Implications of multiple antimicrobial-resistant enterococci associated with the poultry environment. Food Addit. Contam. 18, 1118-1123. doi: $10.1080 / 02652030110051275$

Jukes, T. H. (1972). Antibiotics in animal feeds and animal production. Bioscience 22, 526-534. doi: 10.2307/1296312

Kav, A. B., Sasson, G., Jami, E., Doron-Faigenboim, A., Benhar, I., and Mizrahi, I (2012). Insights into the bovine rumen plasmidome. Proc. Natl. Acad. Sci. U.S.A. 109, 5452-5457. doi: 10.1073/pnas.1116410109

Kemper, N. (2008). Veterinary antibiotics in the aquatic and terrestrial environment. Ecol. Indic. 8, 1-13. doi: 10.1016/j.ecolind.2007.06.002

Kim, H. B., Borewicz, K., White, B. A., Singer, R. S., Sreevatsan, S., Tu, Z. J., et al. (2012). Microbial shifts in the swine distal gut in response to the treatment with antimicrobial growth promoter, tylosin. Proc. Natl. Acad. Sci. U.S.A. 109, 15485-15490. doi: 10.1073/pnas.1205147109

Knapp, C. W., Dolfing, J., Ehlert, P. A. I., and Graham, D. W. (2010). Evidence of increasing antibiotic resistance gene abundances in archived soils since 1940. Environ. Sci. Technol. 44, 580-587. doi: 10.1021/es901221x

Knapp, C. W., Engemann, C. A., Hanson, M. L., Keen, P. L., Hall, K. J., and Graham, D. W. (2008). Indirect evidence of transposon-mediated selection of antibiotic resistance genes in aquatic systems at low-level oxytetracycline exposures. Environ. Sci. Technol. 42, 5348-5353. doi: 10.1021/es703199g

Kohanski, M. A., DePristo, M. A., and Collins, J. J. (2010). Sublethal antibiotic treatment leads to multidrug resistance via radical-induced mutagenesis. Mol. Cell 37, 311-320. doi: 10.1016/j.molcel.2010.01.003

Kumar, K., Gupta, S. C., Chander, Y., and Singh, A. K. (2005). Antibiotic use in agriculture and its impact on the terrestrial environment. Adv. Agron. 87, 1-54. doi: 10.1016/S0065-2113(05)87001-4

Leibler, J. H., Otte, J., Roland-Holst, D., Pfeiffer, D. U., Magalhaes, R. S., Rushton, J., et al. (2009). Industrial food animal production and global health risks: exploring the ecosystems and economics of avian influenza. Ecohealth 6, 58-70. doi: 10.1007/s10393-009-0226-0

Leverstein-van Hall, M. A., Dierikx, C. M., Cohen Stuart, J., Voets, G. M., van den Munckhof, M. P., van Essen-Zandbergen, A., et al. (2011). Dutch patients retail chicken meat and poultry share the same ESBL genes, plasmids and strains. Clin. Microbiol. Infect. 17, 873-880. doi: 10.1111/j.1469-0691.2011. 03497.x

Levin, B. R., Perrot, V., and Walker, N. (2000). Compensatory mutations, antibiotic resistance and the population genetics of adaptive evolution in bacteria. Genetics $154,985-997$.

Looft, T., Johnson, T. A., Allen, H. K., Bayles, D. O., Alt, D. P., Stedtfeld, R. D., et al. (2012). In-feed antibiotic effects on the swine intestinal microbiome. Proc. Natl. Acad. Sci. U.S.A. 109, 1691-1696. doi: 10.1073/pnas.1120238109

Lorenz, M. G., and Wackernagel, W. (1994). Bacterial gene transfer by natural genetic transformation in the environment. Microbiol. Rev. 58, 563-602.

Martinez, J. L. (2009). Environmental pollution by antibiotics and by antibiotic resistance determinants. Environ. Pollut. 157, 2893-2902. doi: 10.1016/j.envpol.2009.05.051

McKinney, C. W., Loftin, K. A., Meyer, M. T., Davis, J. G., and Pruden, A. (2010). tet and sul antibiotic resistance genes in livestock lagoons of various operation type, configuration, and antibiotic occurrence. Environ. Sci. Technol. 44, 6102-6109. doi: 10.1021/es9038165

Nandi, S., Maurer, J. J., Hofacre, C., and Summers, A. O. (2004). Gram-positive bacteria are a major reservoir of Class 1 antibiotic resistance integrons in poultry litter. Proc. Natl. Acad. Sci. U.S.A. 101, 7118-7122. doi: 10.1073/pnas 0306466101

Novo, A., Andre, S., Viana, P., Nunes, O. C., and Manaia, C. M. (2013) Antibiotic resistance, antimicrobial residues and bacterial community composition in urban wastewater. Water Res. 47, 1875-1887. doi: 10.1016/j.watres.2013. 01.010

Peak, N., Knapp, C. W., Yang, R. K., Hanfelt, M. M., Smith, M. S., Aga, D. S., et al. (2007). Abundance of six tetracycline resistance genes in wastewater lagoons at cattle feedlots with different antibiotic use strategies. Environ. Microbiol. 9, 143-151. doi: 10.1111/j.1462-2920.2006.01123.x

Pei, R., Kim, S.-C., Carlson, K. H., and Pruden, A. (2006). Effect of river landscape on the sediment concentrations of antibiotics and corresponding antibiotic resistance genes (ARG). Water Res. 40, 2427-2435. doi: 10.1016/j.watres.2006.04.017 
Perry, J. A., and Wright, G. D. (2013). The antibiotic resistance mobilome: searching for the link between environment and clinic. Front. Microbiol. 4:138. doi $10.3389 /$ fmicb. 2013.00138

Pontiroli, A., Ceccherini, M.-T., Poté, J., Wildi, W., Kay, E., Nannipieri, P., et al. (2010). Long-term persistence and bacterial transformation potential of transplastomic plant DNA in soil. Res. Microbiol. 161, 326-334. doi: 10.1016/j.resmic.2010.04.009

Price, L. B., Stegger, M., Hasman, H., Aziz, M., Larsen, J., Andersen, P. S., et al. (2012). Staphylococcus aureus CC398: host adaptation and emergence of methicillin resistance in livestock. MBio 3, e00305-e00311. doi: 10.1128/mBio. 00305-11

Pruden, A., Pei, R., Storteboom, H., and Carlson, K. H. (2006). Antibiotic resistance genes as emerging contaminants: studies in northern Colorado. Environ. Sci. Technol. 40, 7445-7450. doi: 10.1021/es0604131

Qu, A., Brulc, J. M., Wilson, M. K., Law, B. F., Theoret, J. R., Joens, L. A., et al. (2008). Comparative metagenomics reveals host specific metavirulomes and horizontal gene transfer elements in the chicken cecum microbiome. PLoS ONE 3:e2945. doi: 10.1371/journal.pone.0002945

Raes, J., and Bork, P. (2008). Molecular eco-systems biology: towards an understanding of community function. Nat. Rev. Microbiol. 6, 693-699. doi: 10.1038/nrmicro1935

Rozen, D. E., McGee, L., Levin, B. R., and Klugman, K. P. (2007). Fitness costs of fluoroquinolone resistance in Streptococcus pneumoniae. Antimicrob. Agents Chemother. 51, 412-416. doi: 10.1128/AAC.01161-06

Rutherford, D. W., Bednar, A. J., Garbarino, J. R., Needham, R., Staver, K. W., and Wershaw, R. L. (2003). Environmental fate of roxarsone in poultry litter. Part II. Mobility of arsenic in soils amended with poultry litter. Environ. Sci. Technol. 37, 1515-1520. doi: 10.1021/es026222+

Sapkota, A. R., Lefferts, L. Y., McKenzie, S., and Walker, P. (2007). What do we feed to food-production animals? A review of animal feed ingredients and their potential impacts on human health. Environ. Health Perspect. 115, 663-670. doi: 10.1289/ehp. 9760

Sarmah, A. K., Meyer, M. T., and Boxall, A. B. A. (2006). A global perspective on the use, sales, exposure pathways, occurrence, fate and effects of veterinary antibiotics (VAs) in the environment. Chemosphere 65, 725-759. doi: 10.1016/j.chemosphere.2006.03.026

Schentag, J. J., Klugman, K. P., Yu, V. L., Adelman, M. H., Wilton, G. J., Chiou, C. C., et al. (2007). Streptococcus pneumoniae bacteraemia: pharmacodynamic correlations with outcome and macrolide resistance-a controlled study. Int. J. Antimicrob. Agents 30, 264-269. doi: 10.1016/j.ijantimicag.2007.04.013

Sengelov, G., Agerso, Y., Halling-Sorensen, B., Baloda, S. B., Andersen, J. S., and Jensen, L. B. (2003). Bacterial antibiotic resistance levels in Danish farmland as a result of treatment with pig manure slurry. Environ. Int. 28, 587-595. doi: 10.1016/S0160-4120(02)00084-3

Shade, A., Caporaso, J. G., Handelsman, J., Knight, R., and Fierer, N. (2013). A meta-analysis of changes in bacterial and archaeal communities with time. ISME J. 7, 1493-1506. doi: 10.1038/ismej.2013.54

Shanmugasundaram, R., Lilburn, M. S., and Selvaraj, R. K. (2011). Effect of recycled litter on immune cells in the cecal tonsils of chickens. Poult. Sci. 91, 95-100. doi: 10.3382/ps.2011-01800

Siefert, J. L. (2009). Defining the mobilome. Methods Mol. Biol. 532, 13-27. doi: 10.1007/978-1-60327-853-9_2

Silbergeld, E., Graham, J., and Price, L. B. (2008). Industrial food animal production, antimicrobial resistance, and human health. Annu. Rev. Public Health 29, 151-169. doi: 10.1146/annurev.publhealth.29.020907.090904

Silveira, E., Freitas, A. R., Antunes, P., Barros, M., Campos, J., Coque, T. M., et al. (2014). Co-transfer of resistance to high concentrations of copper and firstline antibiotics among Enterococcus from different origins (humans, animals, the environment and foods) and clonal lineages. J. Antimicrob. Chemother. 69 899-906. doi: 10.1093/jac/dkt479

Singer, R. S., Ward, M. P., and Maldonado, G. (2006). Can landscape ecology untangle the complexity of antibiotic resistance? Nat. Rev. Microbiol. 4, 943-952. doi 10.1038/nrmicro1553

Skurnik, D., Ruimy, R., Ready, D., Ruppe, E., Bernede-Bauduin, C., Djossou, F., et al. (2010). Is exposure to mercury a driving force for the carriage of antibiotic resistance genes? J. Med. Microbiol. 59, 804-807. doi: 10.1099/jmm. 0.017665-0

Smet, A., Rasschaert, G., Martel, A., Persoons, D., Dewulf, J., Butaye, P., et al. (2011). In situ ESBL conjugation from avian to human Escherichia coli during cefotaxime administration. J. Appl. Microbiol. 110, 541-549. doi: 10.1111/j.1365-2672.2010.04907.x

Smith, M. S., Yang, R. K., Knapp, C. W., Niu, Y., Peak, N., Hanfelt, M. M., et al. (2004). Quantification of tetracycline resistance genes in feedlot lagoons by realtime PCR. Appl. Environ. Microb. 70, 7372-7377. doi: 10.1128/AEM.70.12.73727377.2004

Starr, M. P., and Reynolds, D. M. (1951). Streptomycin resistance of coliform bacteria from turkeys fed streptomycin. Am. J. Public Health Nations Health 41, 1375-1380. doi: 10.2105/AJPH.41.11_Pt_1.1375

Stepanauskas, R., Glenn, T. C., Jagoe, C. H., Tuckfield, R. C., Lindell, A. H., King, C. J., et al. (2006). Coselection for microbial resistance to metals and antibiotics in freshwater microcosms. Environ. Microbiol. 8, 1510-1514. doi: 10.1111/j.14622920.2006.01091.x

Stine, O. C., Johnson, J. A., Keefer-Norris, A., Perry, K. L., Tigno, J., Qaiyumi, S., et al. (2007). Widespread distribution of tetracycline resistance genes in a confined animal feeding facility. Int. J. Antimicrob. Agents 29, 348-352. doi: 10.1016/j.ijantimicag.2006.11.015

Stokstad, E. L. R., and Jukes, T. H. (1958-1959) Studies of the growthpromoting effect of antibiotics in chicks on a purified diet. Antibiot. Ann. 6, 998-1002.

Stolz, J. F., Perera, E., Kilonzo, B., Kail, B., Crable, B., Fisher, E., et al. (2007) Biotransformation of 3-nitro-4-hydroxybenzene arsonic acid (roxarsone) and release of inorganic arsenic by Clostridium species. Environ. Sci. Tech. 41, 818-823. doi: 10.1021/es061802i

Storteboom, H. N., Kim, S.-C., Doesken, K. C., Carlson, K. H., Davis, J. G., and Pruden, A. (2007). Response of antibiotics and resistance genes to high-intensity and low-intensity manure management. J. Environ. Qual. 36, 1695-1703. doi: $10.2134 /$ jeq2007.0006

Teuber, M. (2001). Veterinary use and antibiotic resistance. Curr. Opin. Microbiol. 4, 493-499. doi: 10.1016/S1369-5274(00)00241-1

Tolls, J. (2001). Sorption of veterinary pharmaceuticals in soils: a review. Environ. Sci. Technol. 35, 3397-3406. doi: 10.1021/es0003021

Tuckfield, R. C., and McArthur, J. V. (2008). Spatial analysis of antibiotic resistance along metal contaminated streams. Microb. Ecol. 55, 595-607. doi: 10.1007/s00248-007-9303-5

Vandenberg, L. N. (2014). Low-dose effects of hormones and endocrine disruptors. Vitam. Horm. 94, 129-165. doi: 10.1016/B978-0-12-800095-3.00005-5

van Elsas, J. D., Turner, S., and Bailey, M. J. (2003). Horizontal gene transfer in the phytosphere. New Phytol. 157, 525-537. doi: 10.1046/j.1469-8137.2003. 00697.x

van Loo, I., Huijsdens, X., and Tiemersma, E. (2007). Emergence of methicillinresistant Staphylococcus aureus of animal origin in humans. Emerg. Infect. Dis. 13, 1834-1839. doi: 10.3201/eid1312.070384

Volkova, V. V., Bailey, R. H., and Wills, R. W. (2009). Salmonella in broiler litter and properties of soil at farm location. PLOS ONE 4:e6403. doi: 10.1371/journal.pone.0006403

Waters, A. E., Contente-Cuomo, T., Buchhagen, J., Liu, C. M., Watson, L., Pearce, K., et al. (2011). Multidrug-Resistant Staphylococcus aureus in US meat and poultry. Clin. Infect. Dis. 52, 1227-1230. doi: 10.1093/cid/cir181

Wegener, H. C. (2003). Antibiotics in animal feed and their role in resistance development. Curr. Opin. Microbiol. 6, 439-445. doi: 10.1016/j.mib.2003. 09.009

Wei, S., Morrison, M., and Yu, Z. (2013). Bacterial census of poultry intestinal microbiome. Poult. Sci. 92, 671-683. doi: 10.3382/ps.2012-02822

Wozniak, R. A. F., and Waldor, M. K. (2010). Integrative and conjugative elements: mosaic mobile genetic elements enabling dynamic lateral gene flow. Nat. Rev. Microbiol. 8, 552-563. doi: 10.1038/nrmicro2382

Wright, G. D. (2007). The antibiotic resistome: the nexus of chemical and genetic diversity. Nat. Rev. Microbiol. 5, 175-186. doi: 10.1038/ nrmicrol614

Wu, N., Qiao, M., Zhang, B., Cheng, W.-D., and Zhu, Y.-G. (2010). Abundance and diversity of tetracycline resistance genes in soils adjacent to representative swine feedlots in China. Environ. Sci. Technol. 44, 6933-6939. doi: 10.1021/es 1007802

You, Y., Hilpert, M., and Ward, M. J. (2012). Detection of a common and persistent tet $(\mathrm{L})$-carrying plasmid in chicken-waste-impacted farm soil. Appl. Environ. Microb. 78, 3203-3213. doi: 10.1128/AEM.07763-11

You, Y., Hilpert, M., and Ward, M. J. (2013). Identification of Tet45, a tetracycline efflux pump, from a poultry-litter-exposed soil isolate and persistence of 
tet(45) in the soil. J. Antimicrob. Chemother. 68, 1962-1969. doi: 10.1093/jac/ dkt127

Zhang, X.-X., Zhang, T., and Fang, H. H. P. (2009). Antibiotic resistance genes in water environment. Appl. Microbiol. Biotechnol. 82, 397-414. doi: $10.1007 /$ s00253-008-1829-Z

Zhou, W., Wang, Y., and Lin, J. (2012). Functional cloning and characterization of antibiotic resistance genes from the chicken gut microbiome. Appl. Environ. Microb. 78, 3028-3032. doi: 10.1128/AEM.06920-11

Zhu, Y.-G., Johnson, T. A., Su, J.-Q., Qiao, M., Guo, G.-X., Guo, F., et al. (2013). Diverse and abundant antibiotic resistance genes in Chinese swine farms. Proc. Natl. Acad. Sci. U.S.A. 110, 3435-3440. doi: 10.1073/pnas. 1222743110

Zinsstag, J., Schelling, E., Waltner-Toews, D., and Tanner, M. (2011). From one medicine to one health and systemic approaches to health and well-being. Prev. Vet. Med. 101, 148-156. doi: 10.1016/j.prevetmed. 2010.07.003
Conflict of Interest Statement: The authors declare that the research was conducted in the absence of any commercial or financial relationships that could be construed as a potential conflict of interest.

Received: 14 March 2014; accepted: 22 May 2014; published online: 10 June 2014. Citation: You Y and Silbergeld EK (2014) Learning from agriculture: understanding low-dose antimicrobials as drivers of resistome expansion. Front. Microbiol. 5:284. doi: 10.3389/fmicb.2014.00284

This article was submitted to Antimicrobials, Resistance and Chemotherapy, a section of the journal Frontiers in Microbiology.

Copyright $(\odot 2014$ You and Silbergeld. This is an open-access article distributed under the terms of the Creative Commons Attribution License (CC BY). The use, distribution or reproduction in other forums is permitted, provided the original author(s) or licensor are credited and that the original publication in this journal is cited, in accordance with accepted academic practice. No use, distribution or reproduction is permitted which does not comply with these terms. 